\title{
Cryopyrin-Associated Periodic Syndromes and Treatment Options
}

\author{
Lidija Kareva*, Katarina Stavrik, Kristina Mironska \\ Department of Immunology, University Pediatric Clinic, University “Ss. Cyril and Methodius”, Skopje, Republic of Macedonia
}

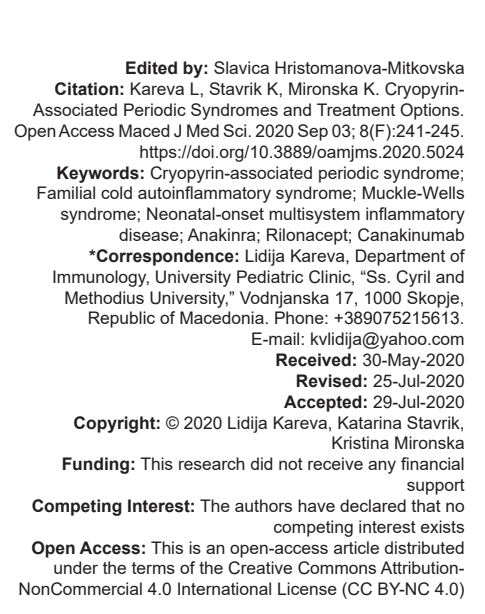

Abstract

Cryopyrin-associated periodic syndromes (CAPSs) are a growing family of autoinflammatory diseases, also known as periodic fever syndromes. There are three forms of CAPS: (1) Familial Cold autoinflammatory syndrome or familial cold urticaria, (2) Muckle-wells syndrome, and (3) neonatal-onset multisystem inflammatory disease or chronic infantile neurological cutaneous articular syndrome. Genetic mutations in the NLRP3 gene were found to be present in most patients. The foremost common findings between all the CAPS disorders are rash, fever which is sometimes present at birth or in early childhood, joint problems, and conjunctivitis. More extreme forms of CAPS include more persistent inflammation that can cause hearing loss and meningitis and can lead to mental and developmental delays. Drugs for CAPS target the source of inflammation - which is the over-production of interleukin 1 B by modified cryopyrin inflammasomes. Three drugs are used to treat CAPS: Rilonacept, canakinumab, and anakirna. With these drugs, the prognosis is greatly improved, with most patients having less frequent episodes, decreased buildup of amyloid in the body, and extended life of severe cases up to adulthood.

\section{Introduction}

Cryopyrin-associated periodic syndromes (CAPSs) are a growing family of autoinflammatory diseases, also known as periodic fever syndromes. Autoinflammatory diseases are a group of disorders characterized by repetitive episodes of systemic and organ-specific inflammation. Unlike autoimmune diseases which are caused by activation of the specific immune system, people with autoinflammatory diseases do not produce autoantibodies or antigenspecific lymphocytes, instead, these diseases are caused by genetic mutations in molecules that regulate the innate immune response [1], [2]. There are three forms of CAPS: (1) Familial cold autoinflammatory syndrome (FCAS) or familial cold urticaria, (2) MuckleWells Syndrome (MWS), and (3) Neonatal-onset multisystem inflammatory disease (NOMID) or chronic infantile neurological cutaneous articular syndrome (CINCA). Genetic mutations in the NLRP3 gene were found to be present in most patients [3], [4], [5], [6]. These three syndromes represent varying degrees of inflammation caused by the same condition with different levels of severity. The NLRP3 gene gives instructions for making a protein called cryopyrin which is one of the regulators of the process of inflammation.
Cryopyrin is included within the get together of a molecular complex called an inflammasome that mediates activation of caspase-1. Caspase- 1 regulates the production of interleukin-1 (IL-1) beta. NLRP3 mutations result in an abnormal cryopyrin structure, leading to abnormally high inflammasome activity response, resulting to overproduction of proinflamatory cytokine IL-1ß [3], [4], [5], [6], [7], [8], [9]. These results are connected with the episodes of fever and damage to the body's cells and tissues. The foremost common findings between all the CAPS disorders are rash, fever which is sometimes present at birth or in early childhood, joint problems, and conjunctivitis. More extreme forms of CAPS include more persistent inflammation that can cause hearing loss and meningitis and can lead to mental and development delays.

\section{Epidemiology}

CAPS is very rare diseases. The incidence in Germany is 0.34 per $10^{6}$ persons-years [10]. Based on that, research in Republic of Macedonia should be 1-2 new patients every 2 years. 


\section{FCAS}

This disorder has autosomal dominant inheritance, and genetic mutation is on the NLRP3 gene. Most of the patients with FCAS can have a normal life and have children so they can pass the genetic mutation through generations. Characteristics of the disorder are recurrent episodes of fever and rash that occurs $1-2 \mathrm{~h}$ after exposure to cold temperature. The start of the disease is under 6 months of age, or sometimes in early childhood. Some patients have a rash display at birth. Many patients have rash each day, but seriously attacks happened after exposure to cold temperature. Sometimes after the occurrence of the rush, there is elevated temperature and arthralgia. Some patients also have abdominal pain, conjunctivitis, sweating, and headache. The duration of the episodes is less or around $24 \mathrm{~h}$. Treatment incorporates warming of the patient, non-steroid anti-inflammatory drugs, corticosteroids, and IL-1 blocking agents to prevent cellular uptake of IL1 ß [4], [11].

\section{MWS}

MWS is a form of CAPS that is caused by is autosomal dominant genetic mutations on the NLRP3 gene. Most families with CAPS have FCAS or MWS and affected individuals of the family frequently share common symptoms. People with MWS have been able to have children which have led to the syndrome being present in some families for many generations. Chronic and recurrent hives on the entire body are present during early childhood. Fevers start in early childhood and are related to flare-ups of symptoms like rashes, joint pains, headaches, and eye inflammation. These symptoms usually last 1-2 days and can be activated sometimes by cold temperatures, stress, or exercise.

Joint pains are not associated with tissue and cartilage damage. Recurrent conjunctivitis is often a problem with MWS, and many patients also have a haze on their corneas. Hearing loss occurs in most patients during early adolescence. Due to chronic high levels of inflammation, some patients with MWS may develop amyloidosis, with presence of amyloid within the kidneys and liver [12], [13].

At present, the best medications found to help that the many sufferers of MWS have been the use of different IL-1ß blocking drugs to prevent the cellular uptake of IL-1ß.

\section{NOMID/CINCA}

NOMID/CINCA has the highest seriousness of chronic inflammation of all the forms of CAPS. It is also caused by mutations in the same genetic region of the NLRP3 gene. NOMID/CINCA symptoms are present at birth, or shortly after, with the hives rash which can increase during times of flare-ups of inflammation, fevers, pain in the joints, headaches, red eyes, and other symptoms. Swelling of the joints is sometimes with changes to the growth cartilage. Central nervous system symptoms may include headaches, stiffness of the neck and nausea, elevated spinal fluid pressures, chronic aseptic meningitis with elevated neutrophils, and eosinophils present in the cerebrospinal fluid. The majority of children have significant mental deficits. During inflammatory episodes, many people with NOMID/CINCA and other forms of CAPS can suffer from conjunctivitis which is not caused by infection, they also have chronic papilledema within the eyes which can lead to a serious loss of vision. Progressive deafness can occur in these patients in early childhood. Some patients have dysmorphical facial characteristics, such as a saddleback nose or frontal bossing, smaller teeth, and other dental anomalies. There is a significant risk for amyloidosis with elevated serum amyloid and kidney damage, and some patients also have enlarged liver and spleen [14], [15]. Treatment has been the use of various IL-1ß-blocking drugs.

The main clinical characteristics of CAPS are presented in Table 1.

Table 1: Clinical characteristics of CAPS

\begin{tabular}{lll}
\hline Familial cold urticaria & Muckle-wells syndrome & $\begin{array}{l}\text { Neonatal-Onset multisystem } \\
\text { inflammatory disease }\end{array}$ \\
\hline Triggered by cold & $\begin{array}{l}\text { Sometimes triggered by } \\
\text { cold }\end{array}$ & Not triggered by cold \\
Recurrent fever & Recurrent fever & Persistent fever \\
Hives & Hives & Hives \\
Arthralgia & Arthritis & Arthritis/joints damage \\
Conjunctivitis & Conjunctivitis, episcleritis, & Conjunctivitis, episcleritis, uveitis, \\
& uveitis & optic atrophy \\
& Hearing loss & Hearing loss \\
& Amyloidosis & Amyloidosis \\
& Headaches & Chronic aseptic meningitis \\
\hline
\end{tabular}

\section{Diagnostic Procedures for Caps}

During acute attacks laboratory tests often reveal signs of non-specific inflammatory markers, such as elevated erythrocyte sedimentation rate (ESR), high C-reactive protein (CRP), anemia, leukocytosis with a high number of polynuclear leukocytes and thrombocytes, and elevated serum amyloid A (SAA) (in MWS and NOMID/CINCA). In the case of NOMID/ CINCA, lumbar punction shows cerebrospinal fluid at high pressure with neutrophils and eosinophils and no infection, while blood elements are rarely present in MWS. The following tests may also be performed: Audiogram which shows high-frequency hearing loss, progressing to bilateral deafness, urinary protein to detect amyloidosis, and kidney biopsy to confirm the presence of amyloid deposits. Genetic testing can be performed using a commercial test for an NLRP3 gene 
mutation and should be done for all patients suspected to have CAPS, but should not be the only basis of diagnosis.

\section{Treatment}

Medications for CAPS target the main source of inflammation which is the over-production of IL $1 ß$ by altered cryopyrin inflammasomes. Three drugs that target $\mathrm{IL}-1$ are approved by the US Food and Drug Administration for the treatment of CAPS. The shortacting recombinant IL-1 receptor antagonist named anakinra was approved for the treatment of patients with NOMID in 2012, and the two long-acting IL-1blocking agents, rilonacept, and canakinumab were approved for the treatment of CAPS in 2008 and 2009.

Anakirna is a recombinant and nonglycosylated synthetic form of human IL-1ß receptor antagonist (II-1 Ra) and acts like the endogenous human II-1RA to inhibit II-1ß binding to the II-1receptor type1 (II-1 RI), which helps to inhibit the biologic activity of II- $1 ß$ in the body. The drug is administered as a daily subcutaneous injection. Rilonacept is an IL-1ß (IL-1ß) blocking medication that inhibits IL-1ß by attaching and neutralizing IL-1ß in the circulating blood. This can prevent the cells from being triggered to activate the increase production of inflammatory mediators and is given as a weekly subcutaneous injection. Canakinumab is a fully-humanized monoclonal antibody against IL-1ß with affinity for human solubile IL-1ß. It is given every 4-8 weeks by subcutaneous injection.

The goals of therapy in CAPS are (a) to improve the disease symptoms, to reduce the attack frequency and duration, (b) to diminish the systemic inflammatory markers in the blood as CRP, ESR, and SAA, and (c) to prevent progression of organ damage.

\section{Caps Treatment-clinical Studies}

Clinical studies assessing the efficacy of anakinra and later studies with the other IL-1blocking agents show significant improvement in the clinical symptoms of CAPS and also improvement in inflammatory markers.

The efficacy of the anakinra has been assessed in case reports [16], as well as several clinical studies. The study on 26 NOMID patients observed for 36-60 months find clinical and laboratory response achieved and sustained in all patients [17]. The study of 12 patients with MWS phenotype up to 14 months on anakinra reported that all patients had a significant improvement at 2 weeks and at the final follow-up. Treatment induced complete and long-lasting resolution of fever, arthralgia/ arthritis, and improvement of conjunctivitis at 2 weeks in all patients. Skin rash resolved in 7 of 8 patients. Amyloidosis improved in 1of the 2 patients with confirmed amyloidosis. Hearing loss resolved in 1 and improved in 1 of 10 individual. Hearing loss worsened in two patients under treatment [18]. Studies in patients with NOMID showed that treatment with anakinra can invert organ inflammation such as aseptic meningitis, papilledema, and cochlear inflammation [19]. Rilonacept was better than to placebo in improving the primary (composite symptom score) and secondary (flare days, single-symptom scores, and disease activity) points in a 24-week study of 47 patients with MWS or FCAS phenotypes [20]. Rilonacept showed improved clinical symptoms induced by cold within days of administration in five patients with observed during 24 months follow-up [11]. Canakinumab achieved complete response in the open-label phase of a 48-week study of 31 patients with MWS and four patients with NOMID. In the randomized phase, $81 \%$ of the patients in the placebo group relapsed, whereas all patients in the drug group remained in remission [21]

The doses of IL-1-blocking therapy are needed to suppress systemic and organ inflammation depend on disease severity and the extent of organ involvement. For anakinra, higher doses up to $10 \mathrm{mg} /$ kg/day [19] have been used, and higher dosing has been investigated for patients with more serious forms of CAPS.

\section{Prognosis}

With suitable medications, most of the patients with FCAS and MWS can have normal life, get married, and have children. NOMID/CINCA patients have more severe form of inflammation through their body which can cause some permanent damage. If early diagnosis and treatment with medications are started, the prognosis is greatly improved, with most patients surviving into adulthood.

\section{Conclusion}

CAPS is a growing family of autoinflammatory diseases, also known as periodic fever syndromes. CAPS is caused by genetic mutations in the NLRP3 gene that regulates the innate immune response which results in a hyperactive cryopyrin protein and an increased inflammatory response, leading to overproduction of pro-inflammatory cytokine IL-1ß. 
These changes result in episodes of fever and damage to the body's cells and tissues. The foremost common findings between all the CAPS disorders are rash, fever which is sometimes present at birth or in early childhood, joint problems, and conjunctivitis. More extreme forms of CAPS include more persistent inflammation that can cause hearing loss, meningitis and can lead to mental and developmental delays.

With medications that target the main source of inflammation which is the over-production of IL $1 ß$, anakinra, rilonacept, and canakinumab, prognosis is greatly improved, with most patients having less frequent episodes of the disease, preventing amyloidosis, and for severe cases - surviving into adulthood.

\section{References}

1. McDermott MF, Aksentijevich I. The autoinflammatory syndromes. Curr Opin Allergy Clin Immunol. 2002;2(6):511-6. PMid: 14752334

2. Hull KM, Shoham N, Chae JJ, Aksentijevich I, Kastner DL. The expanding spectrum of systemic autoinflammatory disorders and their rheumatic manifestations. Curr Opin Rheumatol. 2003;15(1):61-9. https://doi. org/10.1097/00002281-200301000-00011

\section{PMid:12496512}

3. Arostegui JI, Saldaña MD, Pascal M, Clemente D, Aymerich M, Balaguer F, et al. A somatic NLRP3 mutation as a cause of a sporadic case of chronic infantile neurologic, cutaneous, articular syndrome/neonatal-onset multisystem inflammatory disease: Novel evidence of the role of low-level mosaicism as the pathophysiologic mechanism underlying mendelian inherited diseases. Arthritis Rheum. 2010;62(4):1158-66. https:// doi.org/10.1002/art.27342

PMid:20131270

4. Hedrich CM, Bruck N, Paul D, Hahn G, Gahr M, Rösen-Wolff A Mutation negative familial cold autoinflammatory syndrome (FCAS) in an 8-year-old boy: Clinical course and functional studies. Rheumatol Int. 2012;32(9):2629-36. https://doi. org/10.1007/s00296-011-2019-3

PMid:21833523

5. Shpall RL, Jeffes EW, Hoffman HM. A case of familial cold autoinflammatory syndrome confirmed by the presence of a CIAS1 mutation. Br J Dermatol. 2004;150(5):1029-31. https:// doi.org/10.1111/j.1365-2133.2004.05927.x

PMid:15149524

6. Dodé C, Le Dû N, Cuisset L, Letourneur F, Berthelot JM, Vaudour G, et al. New mutations of CIAS1 that are responsible for Muckle-Wells syndrome and familial cold urticaria: A novel mutation underlies both syndromes. Am J Hum Genet. 2002;70(6):1498-506. https://doi.org/10.1086/340786 PMid:11992256

7. Aksentijevich I, Nowak M, Mallah M, Chae JJ, Watford WT, Hofmann SR, et al. De novo CIAS1 mutations, cytokine activation, and evidence for genetic heterogeneity in patients with neonatal-onset multisystem inflammatory disease (NOMID): A new member of the expanding family of pyrin-associated autoinflammatory diseases. Arthritis Rheum. 2002;46(12):33408. https://doi.org/10.1002/art.10688

PMid:12483741
8. Feldmann J, Prieur AM, Quartier P, Berquin P, Certain $S$, Cortis $\mathrm{E}$, et al. Chronic infantile neurological cutaneous and articular syndrome is caused by mutations in CIAS1, a gene highly expressed in polymorphonuclear cells and chondrocytes. Am J Hum Genet. 2002;71(1):198-203. https:// doi.org/10.1086/341357

PMid:12032915

9. Hoffman HM, Patel DD. Genomic-based therapy: Targeting interleukin-1 for autoinflammatory diseases. Arthritis Rheum. 2004;50(2):345-9. https://doi.org/10.1002/art.20032 PMid: 14872474

10. Lainka E, Neudorf U, Lohse P, Timmann C, Bielak M, Stojanov S, et al. Analysis of cryopyrin-associated periodic syndromes (CAPS) in German children: Epidemiological, clinical and genetic characteristics. Klin Padiatr. 2010;222(6):356-61. https://doi.org/10.1055/s-0030-1265181 PMid:21058222

11. Goldbach-Mansky R, Shroff SD, Wilson M, Snyder C, Plehn S Barham B, et al. A pilot study to evaluate the safety and efficacy of the long-acting interleukin-1 inhibitor rilonacept (interleukin-1 trap) in patients with familial cold autoinflammatory syndrome. Arthritis Rheum. 2008;58(8):2432-42. https://doi.org/10.1002/ art. 23620

\section{PMid:18668591}

12. Hawkins PN, Lachmann HJ, Aganna E, McDermott MF. Spectrum of clinical features in Muckle-Wells syndrome and response to anakinra. Arthritis Rheum. 2004;50(2):607-12. https://doi.org/10.1002/art.20033

PMid:14872505

13. Haas N, Küster W, Zuberbier T, Henz BM. Muckle-Wells syndrome: Clinical and histological skin findings compatible with cold air urticaria in a large kindred. Br J Dermatol. 2004;151(1):99104. https://doi.org/10.1111/j.1365-2133.2004.06001.x PMid: 15270877

14. Prieur AM, Griscelli $C$, Lampert F, Truckenbrodt $H$, Guggenheim MA, Lovell DJ, et al. A chronic, infantile, neurological, cutaneous and articular (CINCA) syndrome. A specific entity analysed in 30 patients. Scand J Rheumatol Suppl. 1987;66:57-68. https://doi. org/10.3109/03009748709102523 PMid:3482735

15. Prieur AM. A recently recognised chronic inflammatory disease of early onset characterised by the triad of rash, central nervous system involvement and arthropathy. Clin Exp Rheumatol. 2001;19(1):103-6.

PMid:11247311

16. Hawkins PN, Lachmann HJ, McDermott MF. Interleukin1-receptor antagonist in the Muckle-Wells syndrome. N Engl J Med. 2003;348(25):2583-4. https://doi.org/10.1056/ nejm200306193482523 PMid: 12815153

17. Sibley CH, Plass N, Snow J, Wiggs EA, Brewer CC, King KA, et al. Sustained response and prevention of damage progression in patients with neonatal-onset multisystem inflammatory disease treated with anakinra: A cohort study to determine threeand five-year outcomes. Arthritis Rheum. 2012;64(7):2375-86. https://doi.org/10.1002/art.34409 PMid:22294344

18. Kuemmerle-Deschner JB, Tyrrell PN, Koetter I, Wittkowski H, Bialkowski A, Tzaribachev N, et al. Efficacy and safety of anakinra therapy in pediatric and adult patients with the autoinflammatory Muckle-Wells syndrome. Arthritis Rheum. 2011;63(3):840-9. https://doi.org/10.1002/art.30149 PMid:21360513

19. Neven B, Marvillet I, Terrada C, Ferster A, Boddaert N Couloignier $\mathrm{V}$, et al. Long-term efficacy of the interleukin-1 
receptor antagonist anakinra in ten patients with neonatalonset multisystem inflammatory disease/chronic infantile neurologic, cutaneous, articular syndrome. Arthritis Rheum. 2010;62(1):258-67. https://doi.org/10.1002/art.25057

PMid:20039428

20. Hoffman HM, Throne ML, Amar NJ, Sebai M, Kivitz AJ, Kavanaugh A, et al. Efficacy and safety of rilonacept (interleukin-1 trap) in patients with cryopyrin-associated periodic syndromes:
Results from two sequential placebo-controlled studies. Arthritis Rheum. 2008;58(8):2443-52. https://doi.org/10.1002/art.23687 PMid: 18668535

21. Lachmann HJ, Kone-Paut I, Kuemmerle-Deschner JB, Leslie KS, Hachulla E, Quartier P, et al. Use of canakinumab in the cryopyrin-associated periodic syndrome. N Engl J Med. 2009;360(23):2416-25. https://doi.org/10.1056/nejmoa0810787 PMid: 19494217 